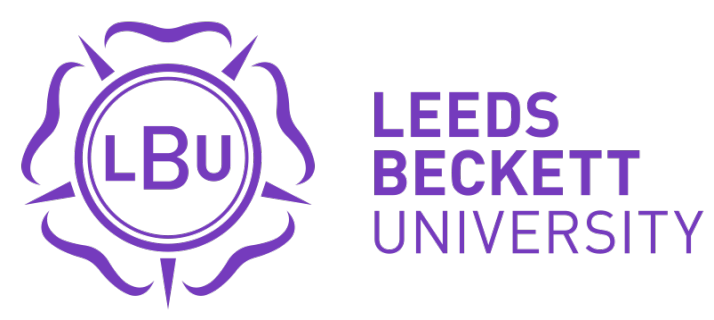

Citation:

Zulu, S and Zulu, E and Mwansa, C (2021) Factors Influencing Intention to Adopt Solar Energy Solutions in Households in Zambia: Insights from the Theory of Planned Behaviour. Smart and Sustainable Built Environment. ISSN 2046-6099 DOI: https://doi.org/10.1108/SASBE-01-2021-0008

Link to Leeds Beckett Repository record:

https://eprints.leedsbeckett.ac.uk/id/eprint/7777/

Document Version:

Article (Accepted Version)

Creative Commons: Attribution-Noncommercial 4.0

The aim of the Leeds Beckett Repository is to provide open access to our research, as required by funder policies and permitted by publishers and copyright law.

The Leeds Beckett repository holds a wide range of publications, each of which has been checked for copyright and the relevant embargo period has been applied by the Research Services team.

We operate on a standard take-down policy. If you are the author or publisher of an output and you would like it removed from the repository, please contact us and we will investigate on a case-by-case basis.

Each thesis in the repository has been cleared where necessary by the author for third party copyright. If you would like a thesis to be removed from the repository or believe there is an issue with copyright, please contact us on openaccess@leedsbeckett.ac.uk and we will investigate on a case-by-case basis. 


\title{
Factors Influencing Intention to Adopt Solar Energy Solutions in Households in Zambia: Insights from the Theory of Planned Behaviour
}

\author{
Sambo Lyson Zulu ${ }^{1}$, Ephraim Zulu², Mwansa Chabala ${ }^{3}$ \\ ${ }^{1}$ Leeds Beckett University School of Built Environment, Engineering and Computing, Leeds, \\ UK \\ ${ }^{2}$ Copperbelt University, School of Built Environment, Construction Economics and \\ Management, Kitwe, Zambia \\ ${ }^{3}$ Copperbelt University, School of Business, Department of Operations and Supply Chain \\ Management, Kitwe, Zambia
}

\begin{abstract}
Purpose - This study examined the factors that influence households' intention to adopt solar energy solutions in Zambia. This, in view of low adoption rates of solar energy solutions even in the wake of a widespread electricity power generation deficit across sub-Sahara Africa (SSA) has plagued the region with daily electricity load shedding lasting several hours at a time. Given the vast potential for solar energy generation in the region, solar energy solutions have become an attractive option to grid-based electricity, and many households have intentions of adopting these solutions.
\end{abstract}

Methodology - Through the lens of the theory of planned behaviour (TPB), the study surveyed adult household members in Zambia who contributed towards the household's income. The participants were selected using the snowballing technique which yielded a sample of 961 respondents. The results were analysed using structural equation modelling.

Results - The results show that attitude, trust, benefits and subjective norms influence the intention to adopt solar energy solutions. Trust and benefits also influence the intention to adopt solar energy solutions indirectly through attitude. Therefore, measures aimed at increasing the adoption of solar energy solutions should focus on improving the attitude, perceived benefits, trust in the solutions and consider subjective norms.

Originality - The findings add to the understanding of the factors that influence the intention to adopt solar energy solutions in Zambia. Therefore, the findings can be used to inform measures aimed at improving solar energy uptake in Zambia. The study also reports on the previously unreported mediating role of attitude towards solar energy solution on the associations between perceived benefits and trust with solar energy solutions adoption intention. Keywords Off-grid solar solutions, Solar energy, Theory of Planned Behaviour Paper type Research paper

\section{Introduction}

Sub-Saharan Africa (SSA) is plagued by an electricity energy crisis characterised by frequent and long periods of power outages due to a deficiency of power generation capacity (Amoah et al., 2019; Nkosi and Dikgang, 2018). For example, in Zambia, the energy crisis from 2015 (Kesselring, 2017; Ngoma et al., 2018) to date has seen household power outages lasting between 8 and 12 hours per day. It is anticipated that the energy crisis in the region will worsen due to a 
demand increase of about 4\% by the year 2040 (Ouedraogo, 2017) and climate change-related factors (Falchetta et al., 2019; Spalding-Fecher et al., 2017; Yamba et al., 2011).

Solar energy solutions present a promising solution to the energy crisis facing SSA. However, some studies have shown that solar solutions are not financially feasible (Baurzhan and Jenkins, 2016; Grimm et al., 2020; Ouedraogo, 2017), while others have argued that they are (Okoye and Oranekwu-Okoye, 2018; Veldhuis and Reinders, 2015). Sievert and Steinbuks (2020) found that off-grid solar systems provide the highest utility for households at low-income levels.

Notwithstanding the uncertainty surrounding the financial feasibility of solar solutions, off-grid solar systems may be the only realistic solution for households in SSA in the face of the energy crisis for reasons of availability and utility (Alrashoud and Tokimatsu, 2019; Qureshi et al., 2017).

However, the adoption of solar energy solutions in SSA is very low for various reasons. It is argued that the adoption of off-grid solar systems in Africa is influenced by technical or financial considerations and societal practices (Abdullahi et al., 2021; Aggarwal et al., 2019; Boamah and Rothfuß, 2018). Using the value-belief-norm (VBN) theory, Fornara et al. (2016) found that household intention to use renewable energy devices was influenced by moral norms and informational influences. In Pakistan, Qureshi et al. (2017) found that cost was the most significant influence on the adoption of solar systems among households. In Zambia, it was concluded that institutional factors were the main challenges affecting renewable energy adoption (Kachapulula-Mudenda et al., 2018). Several factors that influence the decision to adopt solar energy solutions are behavioural beliefs.

Several studies have reported behavioural factors which influence the intention to adopt solar energy using the theory of planned behaviour (TPB) (e.g. Abreu et al., 2019; Fornara et al., 2016; Irfan et al., 2021; Jabeen et al., 2019; Kim et al., 2014; Korcaj et al., 2015; Lau et al., 2020; Ru et al., 2018). However, most of the studies are from high and middle-income countries which are contextually different from the current study (e.g. Abreu et al., 2019; Fornara et al., 2016; Irfan et al., 2021; Korcaj et al., 2015; Lau et al., 2020). While there are some studies from low-income countries (Pakistan and China), no studies have assessed the behavioural factors which influence households to adopt solar energy solutions in SSA. Therefore, this study assessed the influence of attitude, PBC, subjective norms, perceived benefits, trust and cost on solar energy adoption behavioural intention using an extended theory of planned behaviour (TPB) (Ajzen, 1991; Greaves et al., 2013). Notwithstanding relatively similar studies on the subject from low-income countries, the behavioural constructs in those studies were different from this study. For example, in a similar study, Irfan et al. (2021) assessed the perception of self-effectiveness, awareness, environmental concern, perception of neighbour participation, beliefs about cost, and benefits to adopt solar energy solutions in Pakistan. In another similar study from Pakistan, Jabeen et al. (2019) assessed environmental concern, environmental knowledge, awareness, perceived behavioural control, subjective norms, relative advantage and cost. Also, while some studies assessed the influence of perceived benefits, trust and cost on attitude (e.g. Kim et al., 2014; Korcaj et al., 2015) they did not evaluate the mediation paths.

Therefore, the current study addressed the highlighted knowledge gap by assessing the mediating role of attitude towards solar energy solutions on the association between perceived benefits, trust and cost with solar energy adoption behavioural intention. The study also responded to the contextual research gap by providing evidence of behavioural beliefs (i.e., attitudes, subjective norms, and PBC) which influence households to adopt solar energy solutions in a country in SSA. This was achieved by testing the following hypotheses. 
$\mathrm{H}_{1}$ : There is a significant positive association between attitude and solar energy adoption behavioural intention;

$\mathrm{H}_{2}$ : There is an indirect negative significant association between perceived cost of solar energy solutions and behavioural intention through attitude towards the solar energy solutions;

$\mathrm{H}_{3}$ : There is an indirect positive significant association between perceived trust of solar energy solution and behavioural intention through attitude towards the solar energy solutions;

$\mathrm{H}_{4}$ : There is an indirect positive significant association between perceived benefits of solar energy solutions and solar energy adoption behavioural intention through attitude towards the solar energy solutions;

$\mathrm{H}_{5}$ : There is a positive significant association between subjective norms towards solar energy solutions and solar energy adoption behavioural intention.

$\mathrm{H}_{6}$ : There is a positive significant association between PBC over solar energy solutions and solar energy adoption behavioural intention; and

Factors influencing households' intention to adopt solar energy technologies with a local context could inform policymakers and solar energy solution providers to focus attention and effort while promoting the adoption of solar energy technologies in Zambia. The results also add to the body of knowledge on the intention to use solar energy solutions in SSA, which is absent from extant literature.

This paper is structured as follows. The following section discusses the TPB with the associated empirical findings on solar energy adoption intention and subsequently develops the research hypotheses. This is followed by a methodology section that explains the study's design, the procedure followed, selection of the respondents, and the respondents' demographic characteristics. The results are then presented and discussed after which a conclusion is presented.

\section{The Theory of Planned Behaviour (TPB)}

Ajzen (1985) postulated the theory of planned behaviour (TPB), which proposes beliefs as precursors to intention to behave in a particular way. The theory posits that attitude, subjective norms and perceived behavioural control are antecedents to behavioural intentions and behaviours (Ajzen, 1991). The theory was a refinement of the theory of reasoned action initially proposed by Martin Fishbein in 1967 (Ajzen and Fishbein, 1970). The theory of reasoned action was an extension of D.E. Dulanys' theory of propositional control (Ajzen, 1991; Ajzen et al., 1970; Bonfield, 1974). Dulanys' theory of propositional control was concerned with verbal conditioning and concept learning (Bonfield, 1974). Fishbein (1967) applied the theory of propositional control to attitudes and behaviours in human action to develop the theory of reasoned action (Bonfield, 1974). The theory of reasoned action posits that a person's behaviour is influenced by his behavioural intention, which is determined by his attitude toward the act and by his beliefs about other players' expectations, i.e., social normative beliefs (NBs) (Ajzen et al., 1970). The theory of planned behaviour expanded the theory of planned action by adding the concept of perceived behavioural control (Ajzen, 1991). Revisions to the traditional behaviour predicting theories were necessitated by the theories' continued failures to predict specific behaviours. The subsequent theory of planned behaviour by Ajzen (1991) remains the predominant theory for predicting human planned behaviour. The TPB and its relationship to the theory of reasoned action can be seen in Insert Figure 1. 
The TPB has dominated research on behavioural intention for the last three decades. However, the theory has faced some criticism. The TPB initially proposed only three behaviours to influence the intention to behave a certain way. The primary TPB constructs are attitude, perceived behavioural control and subjective norms. However, there have been arguments on the adequacy of the three constructs in terms of whether they are the only behaviours that influence the intention to act in a particular way. Ajzen (1991, p. 199) explained that the theory is "in principle, open to the inclusion of additional predictors if it can be shown that they capture a significant proportion of the variance in intention or behaviour after the theory's current variables have been taken into account".

\section{Behaviour}

Behaviour is the plain acts of an individual (Albarracín et al., 2018). The prediction of behaviour is important in social science when interventions are required to influence subsequent behaviour. Fishbein and Ajzen (1974) argued that aggregating different behaviours produced a reliable prediction of subsequent behaviour based on the aggregation principle. This was in contrast to the previous practice of behaviour prediction based on trait theory and attitudes. Research evidence has shown that under specific circumstances, behavioural intention is a reliable predictor of subsequent behaviour.

\section{Behavioural Intention}

Behavioural intention (BI) is the willingness to perform a behaviour and is often a result of broader goals (Glasman and Albarracín, 2006). Many research findings have shown that BI is a significant predictor of subsequent actual behaviour (e.g. Perri et al., 2020). In the TPB, behavioural intentions capture the motivational factors which would influence behaviour and so accounts for willingness and the effort with which one is prepared to exert in achieving the behaviour (Ajzen, 1991). It is premised on the logic that the more willing and motivated a person is to engage in a behaviour, the more likely they are to actually proceed and engage in the behaviour. The motivational factors that influence behavioural intention are attitude, subjective norms and perceived behavioural control (Ajzen, 1985, 1991; Ajzen and Cote, 2008; Ajzen et al., 1970).

\section{Attitude}

Attitude refers to "the degree to which a person has a favourable or unfavourable evaluation or appraisal of the behaviour in question" (Ajzen, 1991). A distinction can be made between different types of attitudes (Ajzen, 1991), most of which are acquired rather than innate (Ajzen $e t$ al., 2008). Several studies have found that attitude plays a vital role in determining behavioural intention in the adoption of solar energy solutions (e.g. Abreu et al., 2019; Ahmad et al., 2017; Jabeen et al., 2019; Kim et al., 2014; Korcaj et al., 2015; Lundheim et al., 2021; Perri et al., 2020; Reyes-Mercado and Rajagopal, 2017; Ru et al., 2018). Studies on the influence of attitude on renewable energy adoption intention seem to unanimously agree that it is a significant predictor (Abreu et al., 2019; Jabeen et al., 2019; Kim et al., 2014; Korcaj et al., 2015; Ru et al., 2018). For example, while evaluating the conscious and subconscious attitudinal, control and normative beliefs of American homeowners in order to establish factors which influence the intention to 
adopt solar energy Abreu et al. (2019) found that attitude had a significant influence. Similarly, in a study in Pakistan on factors that significantly affect the public's intentions to use solar energy technologies, Jabeen et al. (2019) found that attitude had a significant influence. In South Korea, Kim et al. (2014) also found that it had a significant influence. However, Lundheim et al. (2021) found that attitude only had a marginally significant influence. Notwithstanding, it appears that across all contexts, attitude towards solar energy solutions has a significant influence on the intention to adopt it. Therefore, Kim et al. (2014) suggested that measures aimed at improving the adoption intention of solar energy solutions should also focus on improving the attitude of people towards the solutions.

Therefore, considering the postulation of the TPB and the empirical evidence, it was hypothesised that; $\mathrm{H}_{1}$ : There is a significant positive association between attitude towards solar energy solutions and solar energy adoption intention.

It is accepted that attitudes emanate from beliefs that people have about the object of the attitude (Ajzen, 1991). According to the expectancy-value model, beliefs about at an object are formed by associating them with attributes such as outcomes, characteristics or events (Ajzen, 1991; Ajzen et al., 2008). That is "the subjective value of each attribute contributes to the attitude in direct proportion to the strength of the belief" (Ajzen et al., 2008, p. 291). Attributes are objects, characteristics or events which influence attitude (Ajzen et al., 2008). For solar energy solutions, some of the many attributes likely to influence the attitude towards solar energy solutions are cost, the benefits which would accrue from such solutions, and the trust placed in the solutions.

Finance is one of the main barriers to adopting solar home systems in SSA (Moner-Girona, et al. 2016), so cost is expected to play a significant role in the intention to adopt them. Generally, the cost of solar energy systems are perceived to be higher than any alternatives, and so cost has been found to negatively influence the attitude towards the systems and so the solar energy adoption intention (Irfan et al., 2021; Jabeen et al., 2019; Kim et al., 2014; Korcaj et al., 2015). Nearly all studies find that respondents feel that the cost of solar energy systems is high and so negatively influences adoption intention. For example, Irfan et al. (2021) found that consumer beliefs related to the cost of renewable energy utilisation had a negative effect on utilisation intention. Jabeen et al. (2019) equally found that that cost inhibited the intention to adopt renewable power generation technologies. Irfan et al. (2021) recommended that government should introduce subsidy schemes to encourage domestic consumers to use renewable energies. On the other hand, Korcaj et al. (2015) argued that cost is only an issue in the absence of value and so the question should be about how to create value to offset the cost. Therefore, it was hypothesised that: $\mathrm{H}_{2}$ : There is an indirect negative significant association between perceived cost of solar energy systems and solar energy adoption intention through attitude towards solar energy systems.

Other than cost, it is expected that the perceived benefits of using solar energy systems and their trustworthiness influence the attitude towards the systems and subsequently adoption intention. Using the TPB, a study to assess the intention of the general public to use solar energy in South Korea found that perceived benefits, and trust, significantly contributed to the public attitude toward solar energy technologies while public attitude, satisfaction and perceived cost significantly predicted the intention to use solar energy (Kim et al., 2014). However, Irfan et al. (2021) found that the perceived benefits of using renewable energy solutions did not significantly influence the intention to use renewable energies in Pakistan. Considering the local context of the current study, it was expected that perceived benefits and trust of the solar energy system would influence people's attitude towards solar energy technologies. This is based on the public's displeasure with the power supply company due to widespread electricity load shedding periods. 
Therefore, it was hypothesised that; $\mathrm{H}_{3}$ : There is an indirect positive significant association between perceived trust in solar energy systems and solar energy adoption intention through attitude towards solar energy solutions; and $\mathrm{H}_{4}$ : There is an indirect positive significant association between perceived benefits in solar energy solutions and solar energy adoption intention through attitude towards solar energy solutions;

\section{Subjective Norms}

Subjective norms $(\mathrm{SN})$, also referred to as normative beliefs, "refer to the perceived social pressure to perform or not to perform the behaviour" (Ajzen, 1991). They assess whether important referent individuals or groups would commend or condemn performing the particular behaviour (Ajzen, 1991). The opinion of individuals considered important creates a social pressure to conform to the perception of these people. Subjective norms have been argued to influence behavioural intention (Ajzen, 1985, 1991; Ajzen et al., 2008). This is because generally, the more the social pressure ( $\mathrm{SN}$ ) to engage in a particular behaviour, the greater will be the behavioural intention (Ajzen, 1991)

Several empirical findings have supported this argument by showing that $\mathrm{SN}$ is a significant predictor of intention to engage in a behaviour (Abreu et al., 2019; Korcaj et al., 2015; Lau et al., 2020; Perri et al., 2020). For example, in a survey of homeowners in Germany, and while investigating the intention to purchase a solar energy system, Korcaj et al. (2015) found that subjective norms were a strong predictor. On the other hand, Ru et al. (2018) distinguished two types of subjective norms: subjective inductive norms and subjective descriptive norms. Subjective injuctive norms refer to peoples' perception of behaviours that are approved or disapproved by revered people, while subjective descriptive norms refer to perceptions of what behaviours are typically performed by revered people. It was found that subjective injuctive norms did not influence energy saving intention while subjective descriptive norms did. In this case, it turns out that even when it is perceived that important revered people engage in energysaving behaviours, other people are not necessarily persuaded to do likewise. This finding was surprising because it was hypothesised that even subjective injunctive norms would influence behaviour intention. Owing to SN's positive influence on the purchase intention of solar systems, Korcaj et al. (2015) recommended informing homeowners about nationwide solar system adoption rates even if this is uncommon in someone's neighbourhood or region. This can contribute to increasing subjective norms because direct observation of adoption behaviour by is not necessary.

Therefore, considering the postulation of the TPB and the empirical evidence, it was hypothesised that; $\mathrm{H}_{5}$ : There is a positive significant association between $\mathrm{SN}$ towards solar energy solutions and their adoption intention

\section{Perceived Behavioural Control}

Perceived behavioural control (PBC) represents the amount of control one has over the behaviour (Ajzen, 1985, 1991; Ajzen et al., 2008). As opposed to focusing on the actual control a person has over a behaviour, the TPB focuses on the amount of perceived control one has over the behaviour. This is referred to as perceived behavioural control (PBC). PBC "refers to people's perception of the ease or difficulty of performing the behaviour of interest" (Ajzen, 1991, p. 184). PBC is premised on the rationality that when an individual has control over factor which would affect the decision to engage in the behaviour, they are more likely to subsequently engage in the behaviour as opposed to when they have little to no control at all. Perception of control and not actual control is used in the TPB because it is easier and sometimes more accurate to measure the perceived control as opposed to the actual control, and empirical evidence has shown that it is a reliable substitute for actual control (Ajzen, 1991). PBC has the 
added advantage of including anticipated impediments and obstacles that actual control may not account for.

Some studies show that PBC is a significant predictor of behavioural intention (Jabeen et al., 2019; Lundheim et al., 2021; Perri et al., 2020; Ru et al., 2018). In a study on intention to become pilot customers to install solar panels in a Nordic country, Lundheim et al. (2021) found that PBC had the highest influence. Ru et al. (2018) equally found that PBC was the most decisive factor for the individual energy-saving intention in eastern China. Perri et al. (2020) also found that PBC positively influenced the intention to adopt "smart consumption and production behaviours" in a study of individual-level motivational factors that affect adoption intention in Italy. Subsequently, it has been recommended that it is important to increase PBC over solar adoption intention by removing perceived barriers to increase the adoption rate of solar energy solutions (Jabeen et al., 2019; Ru et al., 2018).

However, some studies have found that PBC does not significantly influence behavioural intention (Abreu et al., 2019; Huang et al., 2020). In a comparative study of American homeowners on the intention to purchase two kinds of solar energy systems, Abreu et al. (2019) found that PBC did not influence purchase intention. Similarly, in a study of solar energy systems cognition on household energy use behaviour, Huang et al. (2020) found that PBC did not significantly influence. It is not clear why there are conflicting results in studies on the influence of $\mathrm{PBC}$ on renewable energy adoption intention. Notwithstanding, considering the postulation of the TPB and the context of the present study, it was hypothesised that; $\mathrm{H}_{6}$ : There is a positive significant association between PBC over solar energy solution adoption and solar energy solutions adoption intention.

Based on the hypothesised relationships, the proposed conceptual model for the study is shown in Insert Figure 2. The model is an expansion of the traditional TPB model with the addition of three constructs, namely, Trust, Cost, and Benefit, which are hypothesised to be attributes of attitude.

Insert Figure 2: The research conceptual model

\section{Methods}

\section{Study design}

The study started with a review of the literature to identify factors that influence the decision to adopt solar energy solutions. The literature revealed that the factors are mostly influenced by behavioural and societal factors rather than technical ones. Subsequently, the TPB is the most frequently used theoretical framework for assessing these factors. Consequently, this study adopted the TPB to establish the factors that influence the decision to adopt solar energy solutions in Zambia. Therefore, the traditional constructs of attitude, PBC and subjective norms were included in the conceptual model. The literature review also showed that other factors beyond those traditionally included in the TPB, such as perceived benefits, trust and cost, also influence solar energy adoption behavioural intention. Therefore, these were also included in the model with seven constructs shown in Figure 2.

\section{Instruments Design}


The data collection instrument for the study was a self-administered questionnaire. Five out of the seven scales were adopted from existing scales and adapted to the local context. These are the scales for behavioural intention, attitude, perceived cost, perceived benefits and perceived trust which were adopted from Park and Ohm (2014). It was considered appropriate to adopt measures from existing instruments because several studies have measured the TPB constructs with the measures from Park et al. (2014) found to be fairly frequently used and so widely validated. The adaptation of the instruments mostly involved including country-specific institutions and emphasising the country context in the measurement items. The scale for behavioural intention had 6 items, the attitude had 5 items, the perceived trust had 5 items, perceived benefits had 8 items, and perceived cost had 5 items. Three sample items from the resulting scales are shown in Insert Table 1. The scales for perceived behavioural control and subjective norms were developed by the authors. The recommended procedure of 1) identify and define practicable characteristics; 2) operationalise selected variables; 3) investigate the reliability of the selected factors; 4) conduct a pre-test and analyse the data and; 4) administer the main survey were followed. Identification, definition and operationalisation of the variables was based on the conceptualisation of subjective norms and PBC by Ajzen (1985) and Ajzen (1991). For example, subjective norms were obtained by asking respondents to rate the extent to which "important people" would approve or disapprove of their performing the particular behaviour (Ajzen, 1991) while PBC was obtained by probing the extent to which the respondents felt they had control over factors which would hinder their decision to adopt solar energy solution. An initial investigation of the face validity and reliability was done by a round table discussion of the resulting measurement items by the authors. Sample items from the resulting scales are shown in Insert Table 1. All, the instrument was anchored on a 5 -point Likert scale with $5=$ strongly agree; 4=agree; $3=$ neutral; $2=$ disagree; and $1=$ strongly disagree.

\section{Procedures and participants}

A pre-test was conducted in line the recommended procedure for developing questionnaires. This was done to check the validity and reliability of both the adapted instruments and those developed by the authors. The self-administering questionnaire was created in Google Forms ( and circulated via email and WhatsApp (C) social media. The use of online resources was preferred because of low cost, ease of use and convenience associated with them as compared to the traditional paper-based self-administering questionnaires. The WhatsApp $\bigodot$ platform was preferred over other social media because of its popularity in Zambia. The Google Forms@ link was deactivated after an initial sample of 80 was achieved in order to pre-test the instruments. Exploratory factor analysis (EFA) and validity and reliability statistics were computed on the pretest sample. Minor modifications were performed on the initial instruments in line with the results of the pre-test analysis. The Google Forms $\mathbb{C}$ link was reactivated, and the final version of the questionnaire was then circulated via email and WhatsApp(C) social media.

The study's target population were adult members of households in Zambia who contributed towards the household's income. The non-probability snowball sampling technique was used to recruit the respondents. This was achieved by circulating the questionnaire link to an initial list of contacts known to the researchers with a request to further share the link with their contacts. Snowballing was preferred because it was anticipated that the questionnaire link would subsequently reach a much larger audience and ensure a sufficiently large sample. Ten Research assistants, who were students pursuing masters degrees, were in gainful employment and contributing to their households' income, were employed also to circulate the link to their contacts. The assistants were asked to follow up the respondents with reminders to complete the 
questionnaire and request their contacts to also circulate the link to others. Any form of probability sampling was not possible because a list of members of households is not available in any form in Zambia. The respondents were informed of their right to not participate in the study and to withdraw from the study at any time if they decided to do so. The respondents were also assured of anonymity and confidentiality in the treatment of their responses.

Insert Table 1: Measurement instrument sample items

\section{Demographic statistics of the sample}

Table 2 shows the demographic characteristics of the sample. The sample was primarily male $(60.5 \%)$, with the majority having at least a college diploma or higher education attainment $(87.9 \%)$. The majority of the respondents lived in rented accommodation $(58.4 \%)$, with a relatively large number living in owned accommodation $(33.7 \%)$. The relatively large number of respondents living in self-owned accommodation may be attributed to the popular practice of self-built housing popularised by the liberalisation of the housing sector by stimulating private sector investment and promoting homeownership in the mid-1990s. Semi-detached flats or blocks of flats are the more popular type of accommodation (25.4\%). The majority of the respondents $(65.4 \%)$ are in formal employment, and the majority $(76.4 \%)$ also earn below 750 USD per month. This is expected, considering that Zambia is a low-income country. The majority of the households have between 3 and 7 persons per households $(75.7 \%)$.

Insert Table 2: Sample demographic characteristics

\section{Results}

Insert Table 3 shows the results of the reliability and validity statistics of the measurement instrument. Reliability was assessed using Cronbach's alpha and Composite Reliability (CR), while validity was assessed using Average Variance Extracted (AVE). Cronbach's alpha for all constructs ranged between .811 and .937 , and so all the constructs met the threshold of .70 recommended by Byrne (2006). Hulland (1999) recommended a threshold of .60 for CR, and all the constructs exceeded this threshold. Therefore, based on Cronbach's alpha and the CR, the study constructs exhibit good reliability. Fornell and Larcker (1981) recommend AVE values to be greater than .50 . However, one construct fell below this threshold. Values of AVE less than 0.50 but greater than 0.40 are also considered acceptable when other measures of validity and reliability are satisfactory because AVE is often too strict, and CR alone can be used to assess reliability (Malhotra and Dash, 2011; Zulu et al., 2018). Therefore, the scales for the study are reliable.

Insert Table 3: Reliability and Validity Statistics 
The constructs were further assessed for discriminant validity. For discriminant validity to exist, the $A V E$ 's square root should be less than the shared variance (inter-correlation) between the two constructs (Fornell et al., 1981). Evidence of discriminant validity can be seen in

Insert Table 4, which shows the AVE's square root in bold and the inter-construct correlations in the remainder of the table. All the inter-construct correlations are less than the square root of the AVE indicating good discriminant validity. Further, all the inter-construct correlations are less than .80 , suggesting that there is no multi-collinearity among them.

\section{Insert Table 4: Inter-Construct Correlations and Discriminant V alidity}

Structural equation modelling (SEM) was used to establish the factors which influence the intention to adopt solar energy solutions. SEM was the preferred data analysis technique because of its ability to estimate multiple and interrelated dependencies, such as those in the conceptual model, in a single analysis. Before assessing the structural relationships among the constructs, the measurement model was assessed for model fitness. This two-step approach was suggested by Anderson and Gerbing (1988). The measurement model was assessed for fitness with thresholds as suggested by $\mathrm{Hu}$ and Bentler (1999). The recommended fit indices and the measurement model fit indices are shown in Table 5. All but one index exceeded the minimum recommended thresholds. The chi-square failed to meet the threshold of being non-significant. The chi-square is criticised for being almost always significant for large samples. The Relative Normed Chisquare reduces the effect of the sample size on the chi-square statistics and so is a better measure of fitness than the chi-square when large samples are used (Byrne, 2006; Hu et al., 1999). Therefore, the measurement model exhibits a good fit to the empirical data.

The structural model fit was evaluated, and the relationships between the study constructs assessed through path modelling. The structural model also showed a good fit based on suggested thresholds (Hu et al., 1999). All the fit indices retained exactly the same values as the measurement model

Insert Table 5: Structural Model Fit Indices

\section{Hypothesis Evaluation}

The structural path coefficients from the SEM model used to evaluate the hypotheses are shown in

Insert Table 6. The first hypothesis $\left(\mathrm{H}_{1}\right)$ postulated that there is a positive significant association between ATT and BI. Consistent with the hypothesis, the association is significant $\left(\mathrm{H}_{1}, \mathrm{R}^{2}=.342\right.$, $p<.001)$. It was also hypothesised $\left(\mathrm{H}_{5}\right)$ that $\mathrm{PBC}$ would have a significant positive association with BI. Contrary to expectation, the hypothesis was not significant $\left(\mathrm{H}_{5}, \mathrm{R}^{2}=.030, p=.260\right)$. It was also hypothesised $\left(\mathrm{H}_{6}\right)$ that $\mathrm{SN}$ would have a significant positive association with $\mathrm{BI}$. Results support the hypothesis $\left(\mathrm{H}_{6}, \mathrm{R}^{2}=.029, p<.001\right)$. 
Other associations show that TRST, BNFT and CST were significantly associated with $A T T$ $\left(\mathrm{R}^{2}=.400, p<.001 ; \mathrm{R}^{2}=.432, p<.001 ; \mathrm{R}^{2}=.14, p<.001\right.$, respectively), which is consistent with expectation. TRST and BNFT were significantly associated with $B I\left(\mathrm{R}^{2}=.109, p=.011\right.$ and $\mathrm{R}^{2}=.152, p<.001$, respectively), which is also consistent with expectation while, contrary to expectation, CST was not statistically significantly associated with BI $\left(\mathrm{R}^{2}=-.002\right.$, $\left.p=.944\right)$. These results are shown in

\section{Insert Table 6.}

Insert Table 6: Hypothesis Evaluation

\section{Mediation paths}

Results of the mediation paths in the structural model are shown in Table 7 and Table 8 . The direct effect of TRST on BI was significant (direct, $b=.424, p<.001$ ) and the indirect effect through ATT was also significant (indirect effect, $b=.124, p<.001,95 \% \mathrm{CI}=.082$ to .166). The direct effect of BNFT on BI was significant (direct, $b=.424, p<.001$ ) and the indirect effect through ATT was also significant (indirect effect, $b=.113, p<.001,95 \% \mathrm{CI}=.075$ to .151 ). The direct effect of CST on BI was not significant (direct, $b=-.002, p=.944$ ) while the indirect effect through ATT was significant (indirect effect, $b=.039, p<.001,95 \% \mathrm{CI}=.021$ to .057 ).

Insert Table 7: Direct Effects of the Mediation Paths

Insert Table 8 : Indirect Effects of the Mediation Paths through Attitude

\section{Discussions}

\section{Attitude and behavioural intention}

Research results show that attitude significantly influenced the intention to adopt solar energy solutions $\left(\mathrm{R}^{2}=.342\right)$, which is in tandem with similar studies (e.g. Abreu et al., 2019; Korcaj et al., 2015; Ru et al., 2018). This means that respondents generally had a positive appraisal of solar energy solutions, leading them to have a positive attitude. The positive attitude subsequently positively influenced their intentions of adopting solar energy technologies. Since attitudes are formed by beliefs such as outcomes, characteristics or events (Ajzen, 1991), the respondents likely like the outcomes and characteristics of solar energy solutions. Considering the energy crisis facing SSA, which is characterised by electricity load shedding of up to 12 hours in some instances, it was expected that respondents would have a positive attitude towards solar energy solutions which provide a viable alternative to the unreliable grid electricity. Therefore, this finding is not surprising but emphasises the relevance of attitude towards solar energy solutions in promoting the adoption of solar energy systems in Zambia. 


\section{Perceived behavioural control and behavioural intention}

While it was expected that $\mathrm{PBC}$ would have a significant positive association with behavioural intention, the results are contrary to this expectation. This means that the extent to which the respondents felt that they could easily adopt solar energy solutions in their homes did not influence their intention to adopt the solutions. This is in contrast to many studies on solar energy technologies, which found that PBC was the most influential predictor on intention (e.g. Lundheim et al., 2021; Perri et al., 2020; Ru et al., 2018) but consistent with other studies which found that it does not (e.g. Abreu et al., 2019; Huang et al., 2020). PBC had a mean score of 2.47, meaning that most the respondents did not feel that there were impediments for them to adopt the solar energy solutions. Considering the availability of many different solar energy solutions in Zambia, some of which are relatively cheap, it is reasonable to deduce that there are relatively few factors that would inhibit people from accessing the solar energy solutions. However, it is surprising that this does not translate into a motivating factor for households to adopt solar energy solutions.

\section{Subjective Norms and behavioural intention}

While the results support the hypothesis that $\mathrm{SN}$ will have a significant positive association with behavioural intention, the association's magnitude is very small $\left(\mathrm{R}^{2}=.029\right)$. This means that, while subjective norms consistently significantly influence behavioural intention, the effect is very small. Notwithstanding, this is consistent with other studies (Abreu et al., 2019; Korcaj et al., 2015; Perri et al., 2020; Ru et al., 2018). Notwithstanding, this suggests that the population in Zambia is influenced by referent individuals on matters to do with solar energy. This means that the opinions of important people on solar energy systems will influence others whether or not to adopt them. These findings have implications on measures aimed at improving solar energy adoption because increasing the level of $\mathrm{SN}$ will increase adoption intention.

\section{Perceived cost, trust and benefits on Attitude}

Attitude is influenced by outcomes, characteristics or events (Ajzen, 1991) and specifically, trust, benefit and cost were considered as potential attributes likely to influence the attitude towards solar energy solutions. It was expected that the perceived trust and perceived benefits perceived of adopting solar energy solutions would positively influence the attitude towards the solutions, while the perceived cost would significantly negatively influence it. The results support the expectation that trust and benefits influence attitude towards solar energy solutions $\left(\mathrm{R}^{2}=.400\right.$ and $\mathrm{R}^{2}=.434$, respectively). This means that the more trust and benefits individuals feel they can derive from solar energy solutions, the more positive is their attitude towards the solar technology solutions. This is consistent with studies that found that trust and benefits influence attitude (e.g. Kim et al., 2014; Korcaj et al., 2015). This finding has important implications on the intention to adopt solar energy systems in Zambia because increasing the perception of trust and benefits of solar energy systems will lead to an improved attitude towards solar energy systems. This is important because the attitude towards solar energy systems was found to be the largest influence on adoption intention.

No studies were found which reported on the association between cost and attitude. When looking at cost in relation to solar energy solutions using the TPB, extant literature mainly conceptualised cost as influencing behavioural intention directly. Consistent with the expectation, this study found that cost significantly positively influenced the attitude towards solar energy solution $\left(\mathrm{R}^{2}=.144\right)$. This suggests that the more favourable the perception of solar 
energy solutions' cost, the better will be the attitude towards the solutions. The finding has an important implication on measures aimed at improving solar energy systems adoption in Zambia because the attitude towards solar energy systems can be increased by improving the perception of the systems' cost and value.

\section{Perceived cost, trust and benefits on behavioural intention}

Besides influencing attitude, it was expected that attributes of attitude, namely trust, benefit and cost, would also influence behavioural intention directly. Some studies found that cost negatively influenced the intention to adopt solar energy solutions (Jabeen et al., 2019; Kim et al., 2014). No studies were found which reported on the association between trust and behavioural intention. While the association between cost and behavioural intention is negative as expected, it is not statistically significant. This contrasts with Jabeen et al. (2019) and Kim et al. (2014) who found statistically significant negative associations. This means that according to this study, the intention to adopt solar energy solutions is not influenced by the perceived cost of the solutions. Surprisingly, the association is not significant even though it is negative. It may be the case that even though cost is considered an issue, other factors play a more dominant role, and so cost fails to be a significant factor in the intention to adopt solar energy systems. This may be the case because the cost of solar energy systems has seen a drastic decline over the last several years, which is likely to reduce the impact of cost being a significant issue in the decision to adopt the systems. Also, solar energy systems are subsidised in Zambia by zero-rating import duties and some taxes. This has the effect of reducing the cost of the systems, thereby making them more affordable.

Contrary to Irfan et al. (2021) 's finding that perceived benefits of solar energy systems do not influence the intention to adopt them, this study found that they significantly $\left(\mathrm{R}^{2}=.156\right)$ influenced adoption intention. Irfan et al. (2021) argued that the absence of a statistically significant association of perceived benefits with adoption intention might be attributed to low levels of awareness of the benefits of renewable energy because the government had not promoted the benefits of renewable energy over conventional energy, which was cheaper. Therefore, it may be the case that the population of interest for this study in Zambia is more aware of the benefits of solar energy solutions and, therefore, the significant association with adoption intention in contrast with the study by Irfan et al. (2021). This would suggest that perceived benefits of solar energy are likely to influence adoption intention in populations aware of its benefits compared to those that are not. This has implications on measures aimed at improving adoption intention.

Perceived trust also significantly $\left(\mathrm{R}^{2}=.109\right)$ influenced the adoption intention. This is consistent with findings by Kim et al. (2014). This means that the more people trust the solar energy solutions, the more their intention to adopt them. Considering that Zambia is plagued by a severe energy crisis characterised by frequent and long periods of load shedding, it is not surprising that people would have trust in solar energy systems to the extent that it increases their adoption intention. This finding has implications on measures aimed at improving adoption intention in regions where trust in traditional electricity sources has been eroded.

\section{Mediation paths to behavioural intention}

Besides direct associations between perceived cost, trust and benefits of solar energy systems with attitude and with behavioural intention, it was also expected that they would have significant indirect associations with the adoption intention through attitude. This was based on 
the value expectancy model (Ajzen et al., 2008). However, no studies were found which reported mediation paths using the TPB with trust, benefit and cost with behavioural intention through attitude. Findings from this study show that attitude mediates the association between trust and behavioural intention (indirect effect, $b=.124, p<.001,95 \% \mathrm{CI}=.082$ to .166 ) and the effect is that it enhances the association. This means that trust influences solar energy adoption intention by influencing the attitude towards the systems. Because the mediation is enhancing in nature, it means that the effect of perceived trust on solar energy adoption intention is increased by improving the attitude towards the systems than through a direct influence. It also means that perceived trust in solar energy solutions influences the intention to adopt the solutions by eliciting a more positive attitude towards the solar solutions. While it is known that perceived trust influences attitude towards solar energy solutions (e.g. Kim et al., 2014; Korcaj et al., 2015), the mediation relationship was not previously reported in the literature. This finding has implications for measures aimed at increasing solar energy adoption because increasing the trust people have in solar energy systems will lead to a direct increase in adoption intention and lead to an improved attitude towards the systems and a stronger adoption intention of the improved attitude.

Attitude also mediates the association between perceived benefits and behavioural intention (indirect effect, $b=.113, p<.001,95 \% \mathrm{CI}=.075$ to .151). This means that the perception of benefits from solar energy solutions improves the attitude towards the solar solutions. While it is known that perceived benefits influence attitude towards solar energy solutions (e.g. Kim et al., 2014; Korcaj et al., 2015), the mediation relationship was not previously reported in the literature. The finding has implications for improving solar energy systems adoption because increasing the perception of benefits obtained from using solar energy systems will lead to an improvement in the attitude towards the systems and an enhanced adoption intention.

The finding that attitude mediates the relationship between perceived benefits and trust of the solar energy solutions with the intention to adopt the systems has an important theoretical implication. It provides empirical evidence supporting the expectancy-value model and the TBP that attitudes emanate from beliefs and that beliefs are associated with attributes such as outcomes. In this case, the mediation of attitude in the relationships between perceived benefits and trust shows that attitude is formed by the perception of the benefits and trust of the solar energy solutions and subsequently influences the outcome of adoption intention.

For cost, there being no direct significant association with behavioural intention, there can be no mediation. Therefore, in this study, cost only influenced the attitude towards solar energy solutions, which influences the intention to adopt solar energy solutions without any mediating effect.

\section{Conclusion}

This study assessed factors that influence solar energy systems adoption intention in Zambia to provide a localised contextual understanding of the factors given limited studies on the matter within the SSA region. For SSA, understanding these factors within a local context is essential to promote widespread adoption of solar energy solutions of which the region has vast potential, and more so in the wake of a severe energy crisis facing the region. The study also assessed the mediation of perceived trust, benefits and cost on the association with solar energy adoption intention through attitude towards the systems through the lens of the theory of planned behaviour. A structural model was used to establish the extent to which attitude, subjective norms and perceived behavioural control influence the intention to adopt solar energy solutions. 
Indirect associations between cost, trust, and benefit with intention to adopt solar energy solutions through attitude were also assessed. Results from the study could guide policymakers and solar energy solution providers where to focus attention and effort in order to promote more widespread adoption of solar energy.

Consistent with other studies, the results show that attitude has the largest influence on the intention to adopt solar energy solutions. Therefore, positive attitudes towards solar energy solutions will lead to increased intentions to adopt solar energy solutions. The findings also show that perceived benefits and trust of the solutions influence the attitude towards the solutions and the intention to adopt them directly and indirectly through a mediation path with attitude. An implication of these findings is that efforts to increase the adoption of solar energy solutions in Zambia should focus on improving the attitude people have towards solar energy solutions. One way to achieve this is by creating awareness of the benefits of adopting the solutions and increasing the trust in the solutions. This recommendation is supported by the findings that perceived benefits and trust of the solar energy solutions significantly influence the attitude towards the solutions both directly and indirectly through a mediation path with attitude. The mediating role of attitude in the relationships between perceived benefits and trust of solar energy solutions with adoption intention provides some empirical backing to the expectancyvalue model that attitudes towards solar energy solutions emanate from beliefs about the attributes of the solutions.

Also consistent with other findings, subjective norms influence the intention to adopt solar energy solutions. An implication of this finding is that efforts aimed at improving the adoption of solar energy solutions in Zambia should harness the power of subjective norms by using important esteemed members of society to disseminate information about the benefits of solar energy solutions.

In this study, contrary to other findings, PBC did not influence the intention to adopt solar energy solutions. It is unclear why this is so. Therefore, future studies on factors that influence solar energy adoption in developing countries may focus attention on why PBC seems not to be an influence.

The study has some limitations which could form the starting point for further studies. Notable among the limitations is that by using an online data collection strategy, the survey collected data from what may be considered an affluent section of a population that is otherwise underprivileged. Therefore, the results are not completely representative of a developing country but rather the affluent section of a developing country. While some instruments used in the study were adapted from existing ones, others were specifically created for the study. Therefore, their psychometric properties are not validated and so raise some issues about the validity and reliability of the measures. Future studies can use validated measures to assess the mediation paths found which were previously not reported in the literature to validate the mediation. Notwithstanding these limitations, the study highlights some previously undetected mediation paths among factors that influence solar energy adoption intention when seen through the TPB lens.

\section{References}

Abdullahi, D., Renukappa, S., Suresh, S., and Oloke, D. (2021). "Barriers for implementing solar energy initiatives in Nigeria: an empirical study". Smart and Sustainable Built Environment, abead-of-print(ahead-of-print). doi:https://doi.org/10.1108/SASBE-06-2020-0094 
Abreu, J., Wingartz, N., and Hardy, N. (2019). "New trends in solar: A comparative study assessing the attitudes towards the adoption of rooftop PV". Energy Policy, 128, 347-363. doi:https://doi.org/10.1016/j.enpol.2018.12.038

Aggarwal, A. K., Syed, A. A., and Garg, S. (2019). "Factors driving Indian consumer's purchase intention of roof top solar". International Journal of Energy Sector Management, 13(3), 539-555. doi:https://doi.org/10.1108/IJESM-07-2018-0012

Ahmad, S., Mat Tahar, R. B., Cheng, J. K., and Yao, L. (2017). "Public acceptance of residential solar photovoltaic technology in Malaysia". PSU Research Review, 1(3), 242-254. doi:https://doi.org/10.1108/PRR-11-2016-0009

Ajzen, I. (1985). "From Intentions to Actions: A Theory of Planned Behavior". In J. Kuhl \& J. Beckmann (Eds.), Action Control. Berlin, Heidelberg: Springer. ISBN: 978-3-642-69746-3

Ajzen, I. (1991). "The theory of planned behavior". Organizational Behavior and Human Decision Processes, 50(2), 179-211. doi:10.1016/0749-5978(91)90020-t

Ajzen, I., and Cote, N. G. (2008). "Attitudes and the Prediction of Behavior". In W. D. Crano \& R. Prislin (Eds.), Attitude and Attitude Change. New York: Psychology Press, Taylor and Francis Group. ISBN: 978-1-84169-481-8 (0)

Ajzen, I., and Fishbein, M. (1970). "The prediction of behavior from attitudinal and normative variables". Journal of Experimental Social Psychology, 6(4), 466-487.

doi:https://doi.org/10.1016/0022-1031(70)90057-0

Albarracín, D., Sunderrajan, A., Lohmann, S., Chan, M.-p. S., and Jiang, D. (2018). "The Psychology of Attitudes, Motivation, and Persuasion". In D. Albarracin \& B. T. Johnson (Eds.), The Handbook of Attitudes, Volume 1: Basic Principles: (2nd ed., Vol. 1): Routledge, Taylor \& Francis Group. ISBN: 9781138648265

Alrashoud, K., and Tokimatsu, K. (2019). "Factors Influencing Social Perception of Residential Solar Photovoltaic Systems in Saudi Arabia". Sustainability, 11(19). doi:https://doi.org/10.3390/su11195259

Amoah, A., Ferrini, S., and Schaafsma, M. (2019). "Electricity outages in Ghana: Are contingent valuation estimates valid?". Energy Policy, 135, 110996. doi:https://doi.org/10.1016/j.enpol.2019.110996

Anderson, J. C., and Gerbing, D. W. (1988). "Structural Equation Modeling in Practice: A Review and Recommended Two-Step Approach". Psychol Bull, 103, 411-423. doi:https://doi.org/10.1.1.540.4887

Baurzhan, S., and Jenkins, G. P. (2016). "Off-grid solar PV: Is it an affordable or appropriate solution for rural electrification in Sub-Saharan African countries?". Renewable and Sustainable Energy Reviews, 60, 1405-1418. doi:https://doi.org/10.1016/j.rser.2016.03.016

Boamah, F., and Rothfuß, E. (2018). "From technical innovations towards social practices and socio-technical transition? Re-thinking the transition to decentralised solar PV electrification in Africa". Energy Research \& Social Science, 42, 1-10. doi:https://doi.org/10.1016/j.erss.2018.02.019

Bonfield, E. H. (1974). "Attitude, social influence, personal norm, and intention interactions as related to brand purchase behavior". Journal of Marketing Research, 11(4), 379-389. doi:https://doi.org/10.2307/3151284

Byrne, B. M. (2006). "Structural Equation Modeling with EQS: Basic Concepts, Applications, and Programming " (2 ${ }^{\text {nd }}$ ed.). Mahwah, NJ: Lawrence Erlbaum Associates. ISBN: 978-0-80586372-7

Falchetta, G., Gernaat, D. E. H. J., Hunt, J., and Sterl, S. (2019). "Hydropower dependency and climate change in sub-Saharan Africa: A nexus framework and evidence-based review". Journal of Cleaner Production, 231, 1399-1417. doi:https://doi.org/10.1016/j.jclepro.2019.05.263

Fornara, F., Pattitoni, P., Mura, M., and Strazzera, E. (2016). "Predicting intention to improve household energy efficiency: The role of value-belief-norm theory, normative and 
informational influence, and specific attitude". Journal of Environmental Psychology, 45, 1-10. doi:https://doi.org/10.1016/j.jenvp.2015.11.001

Fornell, C., and Larcker, D. F. (1981). "Evaluating Structural Equation Models with Unobservable Variables and Measurement Error". Journal of Marketing Research, 18(1), 3950. doi:https://doi.org/10.2307/3151312

Glasman, L. R., and Albarracín, D. (2006). "Forming attitudes that predict future behavior: a meta-analysis of the attitude-behavior relation". Psychol Bull, 132(5), 778-822. doi:https://doi.org/10.1037/0033-2909.132.5.778

Greaves, M., Zibarras, L. D., and Stride, C. (2013). "Using the theory of planned behavior to explore environmental behavioral intentions in the workplace". Journal of Environmental Psychology, 34, 109-120. doi:https://doi.org/10.1016/j.jenvp.2013.02.003

Grimm, M., Lenz, L., Peters, J., and Sievert, M. (2020). "Demand for Off-Grid Solar Electricity: Experimental Evidence from Rwanda". Journal of the Association of Environmental and Resource Economists, 7(3), 417-454. doi:https://doi.org/10.1086/707384

Hu, L., and Bentler, P. M. (1999). "Cutoff Criteria for Fit Indexes in Covariance Structure Analysis: Conventional Criteria Versus New Alternatives". Structural Equation Modeling, 6(1), 1-55. doi:https://doi.org/10.1080/10705519909540118

Huang, F., Liu, J., Wang, Z., Shuai, C., and Li, W. (2020). "Of jobs, skills, and values: Exploring rural household energy use and solar photovoltaics in poverty alleviation areas in China". Energy Research \& Social Science, 67, 101517. doi:https://doi.org/10.1016/i.erss.2020.101517

Hulland, J. (1999). "Use of Partial Least Squares (Pls) In Strategic Management Research: A Review of Four Recent Studies". Strategic Management Journal, 20, 195-204. doi:https://doi.org/10.1002/(SICI)1097-0266(199902)20:2<195::AID-SMJ13>3.0.CO;27

Irfan, M., Hao, Y., Ikram, M., Wu, H., Akram, R., and Rauf, A. (2021). "Assessment of the public acceptance and utilization of renewable energy in Pakistan". Sustainable Production and Consumption, 27, 312-324. doi:https://doi.org/10.1016/i.spc.2020.10.031

Jabeen, G., Yan, Q., Ahmad, M., Fatima, N., and Qamar, S. (2019). "Consumers' intention-based influence factors of renewable power generation technology utilization: A structural equation modeling approach". Journal of Cleaner Production, 237, 117737. doi:https://doi.org/10.1016/j.jclepro.2019.117737

Kachapulula-Mudenda, P., Makashini, L., Malama, A., and Abanda, H. (2018). "Review of Renewable Energy Technologies in Zambian Households: Capacities and Barriers Affecting Successful Deployment". Buildings, 8(6). doi:https://doi.org/10.3390/buildings8060077

Kesselring, R. (2017). "The electricity crisis in Zambia: Blackouts and social stratification in new mining towns". Energy Research \& Social Science, 30, 94-102. doi:https://doi.org/10.1016/j.erss.2017.06.015

Kim, H., Park, E., Kwon, S. J., Ohm, J. Y., and Chang, H. J. (2014). "An integrated adoption model of solar energy technologies in South Korea". Renewable Energy, 66, 523-531. doi:https://doi.org/10.1016/i.renene.2013.12.022

Korcaj, L., Hahnel, U. J. J., and Spada, H. (2015). "Intentions to adopt photovoltaic systems depend on homeowners' expected personal gains and behavior of peers". Renewable Energy, 75, 407-415. doi:10.1016/j.renene.2014.10.007

Lau, L.-S., Choong, Y.-O., Wei, C.-Y., Seow, A.-N., Choong, C.-K., Senadjki, A., and Ching, S.L. (2020). "Investigating nonusers' behavioural intention towards solar photovoltaic technology in Malaysia: The role of knowledge transmission and price value". Energy Policy, 144, 111651. doi:https://doi.org/10.1016/j.enpol.2020.111651

Lundheim, S. H., Vesely, S., Nayum, A., and Klöckner, C. A. (2021). "From vague interest to strong intentions to install solar panels on private homes in the North - An analysis of 
psychological drivers". Renewable Energy, 165, 455-463.

doi:https://doi.org/10.1016/i.renene.2020.11.034

Malhotra, N. K., and Dash, S. (2011). " Marketing Research an Applied Orientation". London: Pearson Publishing. ISBN: 9780132279468

Ngoma, R., Tambatamba, A., Oyoo, B., Mulongoti, D., Kumwenda, B., and Louie, H. (2018). "How households adapted their energy use during the Zambian energy crisis". Energy for Sustainable Development, 44, 125-138. doi:https://doi.org/10.1016/i.esd.2018.03.007

Nkosi, N. P., and Dikgang, J. (2018). "Pricing electricity blackouts among South African households". Journal of Commodity Markets, 11, 37-47. doi:https://doi.org/10.1016/i.jcomm.2018.03.001

Okoye, C. O., and Oranekwu-Okoye, B. C. (2018). "Economic feasibility of solar PV system for rural electrification in Sub-Sahara Africa". Renewable and Sustainable Energy Reviews, 82, 2537-2547. doi:https://doi.org/10.1016/j.rser.2017.09.054

Ouedraogo, N. S. (2017). "Modeling sustainable long-term electricity supply-demand in Africa". Applied Energy, 190, 1047-1067. doi:https://doi.org/10.1016/j.apenergy.2016.12.162

Park, E., and Ohm, J. Y. (2014). "Factors influencing the public intention to use renewable energy technologies in South Korea: Effects of the Fukushima nuclear accident". Energy Policy, 65, 198-211. doi:https://doi.org/10.1016/i.enpol.2013.10.037

Perri, C., Giglio, C., and Corvello, V. (2020). "Smart users for smart technologies: Investigating the intention to adopt smart energy consumption behaviors". Technological Forecasting and Social Change, 155, 119991. doi:https://doi.org/10.1016/i.techfore.2020.119991

Qureshi, T. M., Ullah, K., and Arentsen, M. J. (2017). "Factors responsible for solar PV adoption at household level: A case of Lahore, Pakistan". Renewable and Sustainable Energy Reviews, 78, 754-763. doi:https://doi.org/10.1016/i.rser.2017.04.020

Reyes-Mercado, P., and Rajagopal. (2017). "Adoption of renewable energy technologies in Mexico". International Journal of Energy Sector Management, 11(4), 626-649. doi:https://doi.org/10.1108/IJESM-02-2017-0001

$\mathrm{Ru}, \mathrm{X}$., Wang, S., and Yan, S. (2018). "Exploring the effects of normative factors and perceived behavioral control on individual's energy-saving intention: An empirical study in eastern China". Resources, Conservation and Recycling, 134, 91-99. doi:https://doi.org/10.1016/j.resconrec.2018.03.001

Spalding-Fecher, R., Joyce, B., and Winkler, H. (2017). "Climate change and hydropower in the Southern African Power Pool and Zambezi River Basin: System-wide impacts and policy implications". Energy Policy, 103, 84-97. doi:https://doi.org/10.1016/j.enpol.2016.12.009

Tommasetti, A., Singer, P., Troisi, O., and Maione, G. (2018). "Extended Theory of Planned Behavior (ETPB): Investigating Customers' Perception of Restaurants' Sustainability by Testing a Structural Equation Model. ". Sustainability, 10(2580. ). doi:https://doi.org/doi:10.3390/su10072580

Veldhuis, A. J., and Reinders, A. H. M. E. (2015). "Reviewing the potential and costeffectiveness of off-grid PV systems in Indonesia on a provincial level". Renewable and Sustainable Energy Reviews, 52, 757-769. doi:https://doi.org/10.1016/j.rser.2015.07.126

Yamba, F. D., Walimwipi, H., Jain, S., Zhou, P., Cuamba, B., and Mzezewa, C. (2011). "Climate change/variability implications on hydroelectricity generation in the Zambezi River Basin". Mitigation and Adaptation Strategies for Global Change, 16(6), 617-628. doi:https://doi.org/10.1007/s11027-011-9283-0

Zulu, E., Haupt, T., and Tramontin, V. (2018). "Cognitive Loading due to Self-directed Learning, Complex Questions and Tasks in the Zone of Proximal Development of Students". Problems of Education in the 21st Century, 76(6). doi:https://doi.org/10.33225/pec/18.76.864 

Tables and Figures

\section{Figure}

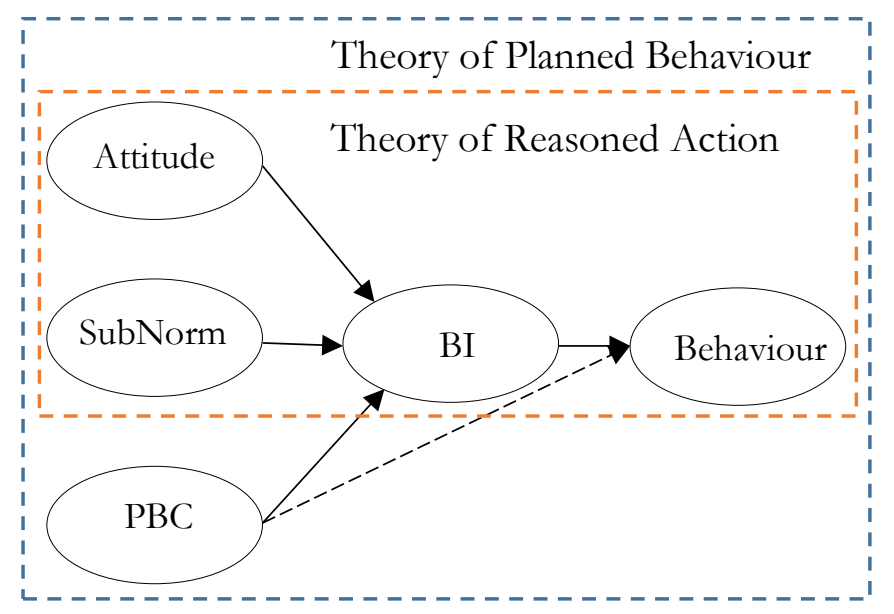

Insert Figure 3: From the theory of reasoned action to the theory of planned behaviour (Tommasetti, Singer, Troisi, \& Maione, 2018) 


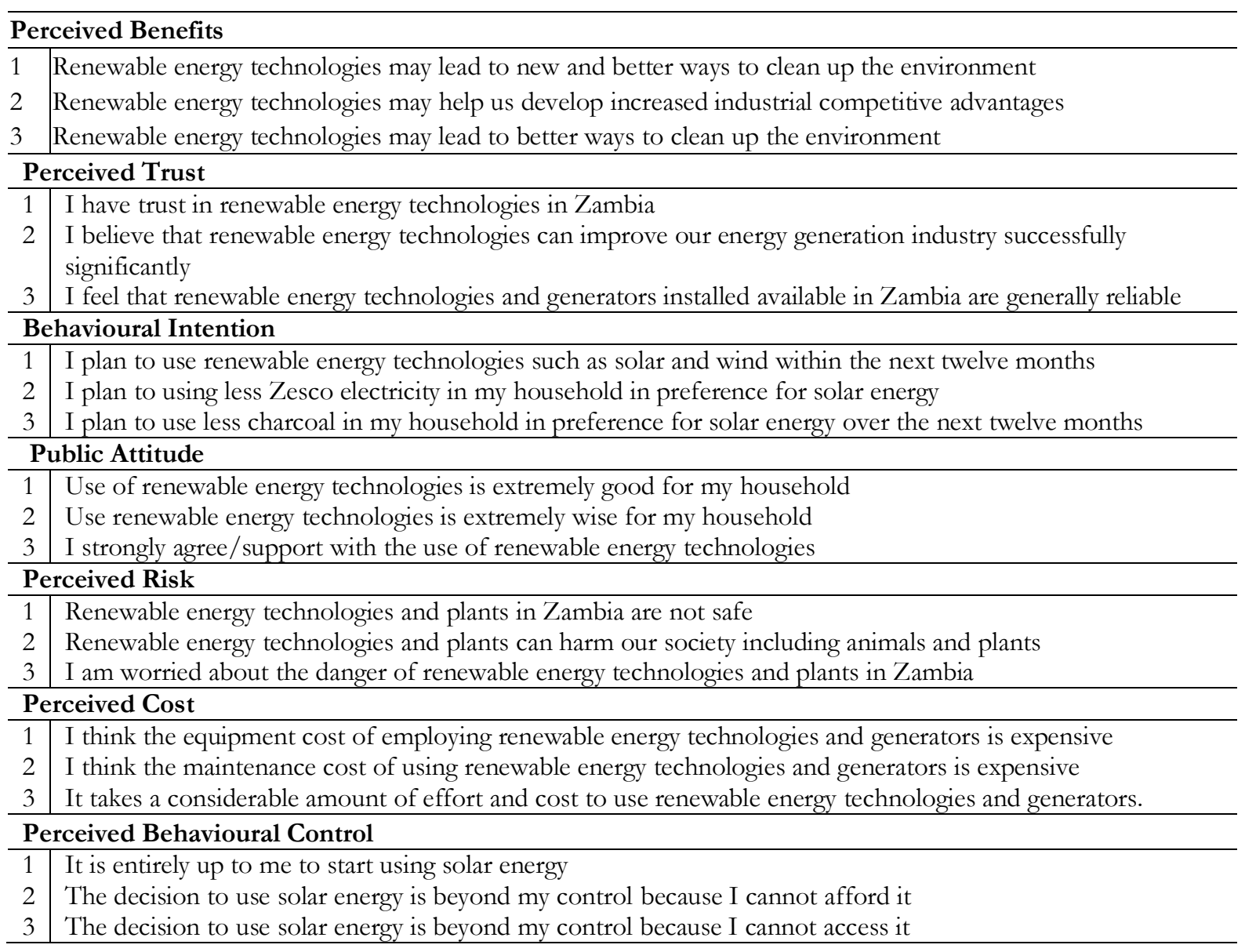


Table 10: Sample demographic characteristics

\begin{tabular}{|c|c|c|}
\hline & Frequency & Percent \\
\hline \multicolumn{3}{|l|}{ Gender } \\
\hline Male & 573 & 60.5 \\
\hline Female & 374 & 39.5 \\
\hline Total & 947 & 100.0 \\
\hline \multicolumn{3}{|l|}{ Education attainment } \\
\hline Primary & 5 & .5 \\
\hline Secondary & 78 & 8.2 \\
\hline Craft certificate & 32 & 3.4 \\
\hline College diploma & 228 & 24.1 \\
\hline University degree & 426 & 45.0 \\
\hline Masters Degree & 154 & 16.3 \\
\hline $\mathrm{PhD}$ & 24 & 2.5 \\
\hline Total & 947 & 100.0 \\
\hline \multicolumn{3}{|l|}{ House Status } \\
\hline Rented & 553 & 58.4 \\
\hline Owned & 319 & 33.7 \\
\hline Institutional & 75 & 7.9 \\
\hline Total & 947 & 100.0 \\
\hline \multicolumn{3}{|l|}{ House type } \\
\hline Semi detached & 200 & 21.1 \\
\hline Flat & 230 & 24.3 \\
\hline Stand-alone House & 478 & 50.5 \\
\hline Small Holder farm & 39 & 4.1 \\
\hline Total & 947 & 100.0 \\
\hline \multicolumn{3}{|l|}{ Employment type } \\
\hline Formal & 619 & 65.4 \\
\hline Informal & 47 & 5.0 \\
\hline Self-employed & 151 & 15.9 \\
\hline Unemployed & 104 & 11.0 \\
\hline Retired & 25 & 2.6 \\
\hline Total & 946 & 99.9 \\
\hline \multicolumn{3}{|l|}{ Income } \\
\hline Below 250 USD & 201 & 21.2 \\
\hline Between 250 and 375 USD & 280 & 29.6 \\
\hline Between 375 and 500 USD & 135 & 14.3 \\
\hline Between 500 and 750 USD & 108 & 11.4 \\
\hline Between 750 and 1, 000 USD & 78 & 8.2 \\
\hline Between 1,000 and 1, 500 USD & 82 & 8.7 \\
\hline Above 1,500 USD & 63 & 6.7 \\
\hline Total & 947 & 100.0 \\
\hline Household size & Mean & Std. Dev. \\
\hline Persons & 5.1 & 2.12 \\
\hline
\end{tabular}


Table 11: Reliability and Validity Statistics

\begin{tabular}{|c|c|c|c|c|c|c|c|c|}
\hline \multicolumn{2}{|c|}{$\begin{array}{l}\text { Research } \\
\text { Constructs }\end{array}$} & Mean & Std. Dev & $\begin{array}{c}\text { Cronbach's } \\
\text { Alpha }\end{array}$ & $\begin{array}{c}\text { Item- } \\
\text { correlations }\end{array}$ & \begin{tabular}{c|} 
Factor \\
Loadings
\end{tabular} & $\mathrm{CR}$ & AVE \\
\hline \multicolumn{9}{|c|}{ Behavioural Intention } \\
\hline 1 & BI1 & 3.37 & 1.096 & \multirow[t]{6}{*}{.896} & .643 & .639 & \multirow[t]{6}{*}{.776} & \multirow[t]{6}{*}{.589} \\
\hline 2 & $\mathrm{BI} 2$ & 3.64 & 1.265 & & .717 & .821 & & \\
\hline 3 & BI3 & 3.65 & 1.256 & & .712 & .760 & & \\
\hline 4 & BI4 & 3.57 & 1.235 & & .756 & .805 & & \\
\hline 5 & BI5 & 3.40 & 1.198 & & .728 & .765 & & \\
\hline 6 & BI6 & 3.59 & 1.203 & & .765 & .799 & & \\
\hline \multicolumn{9}{|c|}{ Attitude } \\
\hline 1 & ATT1 & 3.88 & 1.071 & \multirow[t]{5}{*}{.937} & .776 & .785 & \multirow[t]{5}{*}{.911} & \multirow[t]{5}{*}{.733} \\
\hline 2 & ATT2 & 3.69 & 1.179 & & .844 & .860 & & \\
\hline 3 & ATT3 & 3.91 & 1.176 & & .834 & .885 & & \\
\hline 4 & ATT4 & 4.01 & 1.202 & & .858 & .882 & & \\
\hline 5 & ATT5 & 3.94 & 1.232 & & .840 & .866 & & \\
\hline \multicolumn{9}{|c|}{ Subjective Norm } \\
\hline 1 & SN1 & 3.52 & 1.042 & \multirow[t]{4}{*}{.866} & .718 & .718 & \multirow[t]{4}{*}{.752} & \multirow[t]{4}{*}{.569} \\
\hline 2 & SN2 & 3.47 & 1.173 & & .703 & .870 & & \\
\hline 3 & SN3 & 3.42 & 1.073 & & .755 & .711 & & \\
\hline 4 & SN4 & 3.36 & 1.126 & & .688 & .705 & & \\
\hline \multicolumn{9}{|c|}{ Perceived Behavioural Control } \\
\hline 1 & PBC1 & 2.46 & 1.085 & \multirow[t]{3}{*}{.834} & .694 & .655 & \multirow[t]{3}{*}{.922} & \multirow[t]{3}{*}{.752} \\
\hline 2 & PBC2 & 2.54 & 1.115 & & .692 & .951 & & \\
\hline 3 & PBC3 & 2.43 & 1.086 & & .697 & .960 & & \\
\hline \multicolumn{9}{|c|}{ Trust } \\
\hline 1 & TRST1 & 3.32 & 1.102 & \multirow[t]{5}{*}{.861} & .661 & .703 & \multirow[t]{5}{*}{.736} & \multirow[t]{5}{*}{.555} \\
\hline 2 & TRST2 & 3.59 & 1.248 & & .682 & .858 & & \\
\hline 3 & TRST3 & 3.09 & 1.085 & & .631 & .702 & & \\
\hline 4 & TRST5 & 3.29 & 1.174 & & .709 & .707 & & \\
\hline 5 & TRST5 & 3.45 & 1.240 & & .715 & .744 & & \\
\hline \multicolumn{9}{|c|}{ Cost } \\
\hline 1 & CST1 & 3.34 & 1.178 & \multirow[t]{5}{*}{.811} & .588 & .753 & .611 & .465 \\
\hline 2 & CST2 & 2.82 & 1.160 & & .635 & .722 & & \\
\hline 3 & CST3 & 3.14 & 1.216 & & .686 & .795 & & \\
\hline 4 & CST4 & 2.84 & 1.136 & & .642 & .632 & & \\
\hline 5 & CST5 & 2.60 & 1.121 & & .454 & .452 & & \\
\hline & nefit & & & & & & & \\
\hline 1 & BNFT1 & 3.80 & 1.157 & .930 & .768 & .792 & .803 & .613 \\
\hline 2 & BNFT2 & 3.64 & 1.227 & & .763 & .829 & & \\
\hline 3 & BNFT3 & 3.77 & 1.200 & & .819 & .836 & & \\
\hline 4 & BNFT4 & 3.51 & 1.109 & & .728 & .719 & & \\
\hline 5 & BNFT5 & 3.50 & 1.134 & & .712 & .694 & & \\
\hline 6 & BNFT6 & 3.82 & 1.221 & & .738 & .768 & & \\
\hline 7 & BNFT7 & 3.90 & 1.179 & & .785 & .815 & & \\
\hline 8 & BNFT8 & 3.87 & 1.179 & & .754 & .799 & & \\
\hline
\end{tabular}

$\mathrm{BI}=$ Behavioural intention; $\mathrm{ATT}=$ Attitude; $\mathrm{SN}=$ Sujective norm; $\mathrm{PBC}=$ Perceived behavioural control; TRST $=$ Perceived trust; CST $=$ Perceived cost BNFT $=$ Perceived benefit 
Table 12: Inter-Construct Correlations and Discriminant Validity

\begin{tabular}{|c|c|c|c|c|c|c|c|}
\hline & \multirow[b]{2}{*}{$\mathrm{BI}$} & \multirow[b]{2}{*}{ ATT } & \multirow[b]{2}{*}{$\mathrm{SN}$} & \multicolumn{3}{|c|}{ TRST } & \multirow{2}{*}{$\begin{array}{c}\mathrm{BNF} \\
\mathrm{T}\end{array}$} \\
\hline & & & & PBC & & CST & \\
\hline BI & .767 & & & & & & \\
\hline ATT & $.635^{* *}$ & .856 & & & & & \\
\hline $\mathrm{SN}$ & $.540^{* *}$ & $.503^{* *}$ & .754 & & & & \\
\hline PBC & -.017 & -.057 & -.021 & 867 & & & \\
\hline TRST & $.553^{*}$ & $.635^{*}$ & $.454^{*}$ & - & .745 & & \\
\hline & $*$ & $*$ & $*$ & .039 & & & \\
\hline CST & $.222^{* *}$ & $.302^{* *}$ & $.230^{* *}$ & .008 & $\begin{array}{l}.150 * \\
*\end{array}$ & 682 & \\
\hline $\mathrm{BNF}$ & $.587^{* *}$ & $.679^{* *}$ & $.496^{* *}$ & - & $.586^{*}$ & $.262^{*}$ & .783 \\
\hline $\mathrm{T}$ & & & & .001 & $*$ & & \\
\hline
\end{tabular}

Table 13: Structural Model Fit Indices

\begin{tabular}{llll}
\hline $\begin{array}{l}\text { Model Fit } \\
\text { Index }\end{array}$ & $\begin{array}{l}\text { Acceptable } \\
\text { Threshold }\end{array}$ & $\begin{array}{l}\text { Study } \\
\text { Threshold }\end{array}$ & $\begin{array}{l}\text { Met/Not } \\
\text { Met }\end{array}$ \\
\hline$\lambda^{2}$ & $>.05$ & $<.05$ & Not Met \\
$\lambda^{2} / \mathrm{df}$ & $<3$ & 1.794 & Met \\
CFI & $>.900$ & .950 & Met \\
TLI & $>.900$ & .943 & Met \\
RMSEA & $<.080$ & .046 & Met \\
SRMR & $<.08$ & .050 & Met \\
\hline
\end{tabular}

Table 14: Hypothesis Evaluation

\begin{tabular}{l|l|l|l|l}
\hline \multicolumn{2}{l|}{ Proposed Research Hypotheses } & Coefficient & P-Value & Comment \\
\hline$+\mathrm{H}_{1}$ & ATT $\longrightarrow$ BI & .342 & $<.001$ & Supported \\
$+\mathrm{H}_{2}$ & TRST $\longrightarrow$ ATT $\longrightarrow$ BI & $.124^{*}$ & $<.001$ & Supported \\
$+\mathrm{H}_{3}$ & BNFT $\longrightarrow$ ATT $\longrightarrow$ BI & $.039^{*}$ & $<.001$ & Supported \\
$-\mathrm{H}_{4}$ & CST $\longrightarrow$ ATT $\longrightarrow$ BI & $.113^{*}$ & $<.001$ & Supported \\
$+\mathrm{H}_{5}$ & PBC $\longrightarrow$ BI & .030 & .260 & Not Supported \\
$+\mathrm{H}_{6}$ & SN $\longrightarrow$ BI & .029 & $<.001$ & Supported \\
\cline { 1 - 1 } Other Association & & & \\
\hline+ & TRST $\longrightarrow$ ATT & .400 & $<.001$ & Supported \\
+ & BNFT $\longrightarrow$ ATT & .434 & $<.001$ & Supported \\
+ & CST $\longrightarrow$ ATT & .144 & $<.001$ & Supported \\
+ & TRST $\longrightarrow$ BI & .109 & .011 & Supported \\
+ & BNFT $\longrightarrow$ BI & .156 & $<.001$ & Supported \\
- & CST $\longrightarrow$ BI & -.002 & .944 & Not Supported \\
\hline
\end{tabular}


* Indirect effect

Table 15: Direct Effects of the Mediation Paths

\begin{tabular}{|c|c|c|c|c|c|c|c|}
\hline \multirow{2}{*}{$\frac{\text { Direct }}{\text { ATT }}$} & Effects & Coef. & Std.Err & $\mathbf{z}$ & $P>|z|$ & \multicolumn{2}{|c|}{$[95 \%$ C I $]$} \\
\hline & & & & & & & \\
\hline & TRST & .434 & .041 & 10.66 & $<.001$ & .355 & .514 \\
\hline & CST & .136 & .025 & 5.460 & $<.001$ & .087 & .185 \\
\hline & BENFT & .398 & .034 & 11.54 & $<.001$ & .330 & .465 \\
\hline \multicolumn{8}{|l|}{ BI } \\
\hline & ATT & .285 & .043 & 6.62 & $<.001$ & .200 & .369 \\
\hline & TRST & .098 & .039 & 2.51 & .012 & .021 & .175 \\
\hline & CST & -.002 & .024 & -.070 & .944 & -.048 & .044 \\
\hline & BNFT & .119 & .035 & 3.46 & .001 & .052 & .187 \\
\hline
\end{tabular}

Table 16 : Indirect Effects of the Mediation Paths through Attitude

\begin{tabular}{l|rrrrrrr}
\hline $\begin{array}{l}\text { Indirect } \\
\text { Effects }\end{array}$ & Coef. & Std.Err & $\mathbf{z}$ & $\mathbf{P}>|\mathbf{z}|$ & {$[\mathbf{9 5 \%} \mathbf{C}$ I] } \\
\hline BI & & & & & & & \\
& & & & & & & \\
& TRST & .124 & .021 & 5.780 & $<.001$ & .082 & .166 \\
& CST & .039 & .009 & 4.260 & $<.001$ & .021 & .057 \\
& BENFT & .113 & .019 & 5.860 & $<.001$ & .075 & .151 \\
\hline
\end{tabular}

